\title{
Phytoremediation effect of Medicago sativa colonized by Piriformospora indica in the phenanthrene and cadmium co- contaminated soil
}

\author{
Liang $\mathrm{Li}^{1,2^{*}}$, Pengyue Zhu ${ }^{1,3}$, Xiaoyang Wang ${ }^{1}$ and Zhenhua Zhang ${ }^{1}$
}

\begin{abstract}
Background: The coexistence of polycyclic aromatic hydrocarbons (PAHs) and heavy metals has deleterious effects on environmental quality. Few reports have studied the mechanisms of plant inoculation with Piriformospora indica to remediate PAH-metal co-contaminated soil by analyzing the chemical speciation of the contaminants. This study investigated the influence of the inoculation of Medicago sativa with $P$. indica to remediate soil co-contaminated with phenanthrene (a kind of PAH) and cadmium (a heavy metal) by analyzing plant growth, physiological parameters and chemical speciation in rhizosphere and nonrhizosphere soils.

Results: The presence of $P$. indica significantly increased plant tolerance, chlorophyll $a$, chlorophyll $b$, maximum quantum efficiency of PSII photochemistry and electron transport rate values in phenanthrene- and/or cadmiumcontaminated soil. P. indica inoculation in M. sativa roots increased fluorescein diacetate activities in soils contaminated with phenanthrene, cadmium or both, especially in the nonrhizosphere. The presence of phenanthrene prevented the inoculated plant from accumulating cadmium to some extent, whereas the presence of cadmium did not prevent the degradation of phenanthrene in either the rhizosphere or the nonrhizosphere after $P$. indica colonization. Although the low bioavailability of cadmium in the rhizosphere restricted its transportation into the stem, $P$. indica colonization in plants effectively increased cadmium accumulation in roots in soil co-contaminated with cadmium and phenanthrene.
\end{abstract}

Conclusions: In conclusion, this work provides a theoretical basis for the use of $P$. indica combined with M. sativa for the remediation of PAH-metal co-contaminated soil.

Keywords: Piriformospora indica, Medicago sativa, Phytoremediation, Soil-contamination, Bioavailability, Rhizosphere

\footnotetext{
* Correspondence: 632000520@qq.com

'School of Chemical Engineering and Technology, Hebei University of Technology, Tianjin 300130, China

${ }^{2}$ National-Local Joint Engineering Laboratory for Energy Conservation of Chemical Process Integration and Resources Utilization, Tianjin, China

Full list of author information is available at the end of the article
}

C C The Author(s). 2020 Open Access This article is licensed under a Creative Commons Attribution 4.0 International License, which permits use, sharing, adaptation, distribution and reproduction in any medium or format, as long as you give appropriate credit to the original author(s) and the source, provide a link to the Creative Commons licence, and indicate if changes were made. The images or other third party material in this article are included in the article's Creative Commons licence, unless indicated otherwise in a credit line to the material. If material is not included in the article's Creative Commons licence and your intended use is not permitted by statutory regulation or exceeds the permitted use, you will need to obtain permission directly from the copyright holder. To view a copy of this licence, visit http://creativecommons.org/licenses/by/4.0/. The Creative Commons Public Domain Dedication waiver (http://creativecommons.org/publicdomain/zero/1.0/) applies to the data made available in this article, unless otherwise stated in a credit line to the data. 


\section{Background}

The coexistence of heavy metals and polycyclic aromatic hydrocarbons (PAHs) in soil has caused environmental problems worldwide [1]. Heavy metals and PAHs are human health risks because of their cytotoxicity, mutagenicity and teratogenicity [2]. The co-contamination of heavy metals and PAHs leads to higher toxicity in the environment and increases the difficulty of remediating polluted soil. For example, PAH mineralization was inhibited by a high content of heavy metals in cocontaminated soil [3]. Phytoremediation has been regarded as a cost-effective and environmentally friendly technology and is widely used for soil remediation [4]. Plant-associated microorganisms significantly enhance the PAH and heavy metal removal efficiency of plants $[5,6]$. Removal has two aspects: the fixation and isolation of PAHs and heavy metals by plant roots and the degradation of PAHs by microbes in the rhizosphere [7]. The presence of microorganisms protects plants against damage from plant pathogens and promotes plant growth; in turn, the presence of plants changes the microbial community structure and results in a more conducive environment for soil contaminant removal.

Arbuscular mycorrhizal fungi (AMF) have been used in the phytoremediation of soil contaminated with diesel [8] or heavy metals [9] to enhance plant resistance and heavy metal accumulation capacity. However, AMF are obligate endosymbionts that are unable to be cultivated in vitro. $P$. indica was first discovered in the rhizospheres of woody shrubs in the sandy desert soils of the Thar region of India [10]. The root endophytic basidiomycete $P$. indica belongs to the recently defined order Sebacinales [11]. Species of this order form a novel type of mutualistic mycorrhizal symbiosis and are able to colonize a broad spectrum of plants and convey various beneficial effects to the colonized host plants [12-15]. $P$. indica acts as a bioprotector against pathogens [16], alters plant secondary metabolites [17], increases nutrient uptake, promotes plant growth $[18,19]$, confers drought tolerance to Arabidopsis and barley [20,21], and alleviates salt stress in barley and rice by increasing the activity of detoxifying enzymes as well as the photosynthetic pigment content in colonized plants [22, 23]; $P$. indica is different from AMF that can be cultivated in vitro. Considering the various beneficial effects of $P$. indica, this fungus is regarded as having significant agronomical and ecological application value [24]. However, there are few reports about the utilization of this endophyte for the remediation of soil contaminated by heavy metals and PAHs.

In the remediation of both heavy metals and PAHs, bioavailability determines the remediation efficiency [25, 26]. An increase in organic acid production by roots can effectively increase the bioavailability of heavy metals and PAHs $[27,28]$. P. indica directly increases plant root biomass by producing indole-3-acetic acid (IAA) [29], which increases organic acid production in the roots. Similarly, biosurfactants produced by plant growthpromoting microorganisms (PGPM) can increase the bioavailability of heavy metals and PAHs [27, 28]. In terms of the remediation of heavy metals, the presence of heavy metals stimulated PGPM to produce siderophores, which in turn increased the bioavailability of heavy metals [30-32]. In the case of PAH remediation, plants provide an effective platform for recruiting more efficient microbes to digest or degrade the PAHs [1]. Therefore, PGPM combined with plant roots is an important method of remediating heavy metal- and $\mathrm{PAH}$ contaminated soil.

Some researchers have reported using microorganisms to promote the remediation of single-source contamination caused by heavy metals or PAHs [33]; however, few studies have focused on the influence of plants inoculated with $P$. indica on the chemical speciation of heavy metals and PAHs in soils co-contaminated with metal and PAH. Notably, $P$. indica has been widely studied for its interaction with plants. However, this study focused on different aspects of this topic: (1) investigating the tolerance of $M$. sativa to phenanthrene and cadmium after $P$. indica colonization; (2) speculating on the rhizospheric effect of $P$. indica inoculation by measuring microbial activity and enzyme activity in the rhizosphere and nonrhizosphere; and (3) evaluating the effect of $P$. indica inoculation on the phytoremediation efficiency of $M$. sativa in phenanthrene-cadmium co-contaminated soil.

\section{Results}

\section{$P$. indica inoculation increased the biomass of $M$. sativa in contaminated soil}

The biomass of $M$. sativa was recorded to reflect the tolerance of the plant to pollutants in soil. $P$. indica inoculation significantly promoted both root and stem biomass compared with those of the noninoculated plants (control) (Fig. 1a). In addition, the leaf area was increased compared to that in the control (Fig. 1b). However, reduced biomass (fresh weight) was observed in the $\mathrm{Cd}$, Phe and Phe $+\mathrm{Cd}$ treatments without $P$. indica inoculation, whereas the addition of $P$. indica spores significantly increased the biomass in those treatments (Fig. 1c-d). The data from 1 hundred plants in each different treatment and the related statistical analysis are provided in Fig. 2. The Phe $+\mathrm{Cd}$ treatment led to the most serious biomass reduction compared with the control. In contrast, the plant biomass in the Pir$\mathrm{i}+\mathrm{Cd}$, Piri+Phe and Piri+Phe $+\mathrm{Cd}$ treatments was higher than that in the corresponding treatments without $P$. indica inoculation. Notably, the growth inhibition in the $\mathrm{Cd}$ treatment was greater than that in the Phe treatment. 

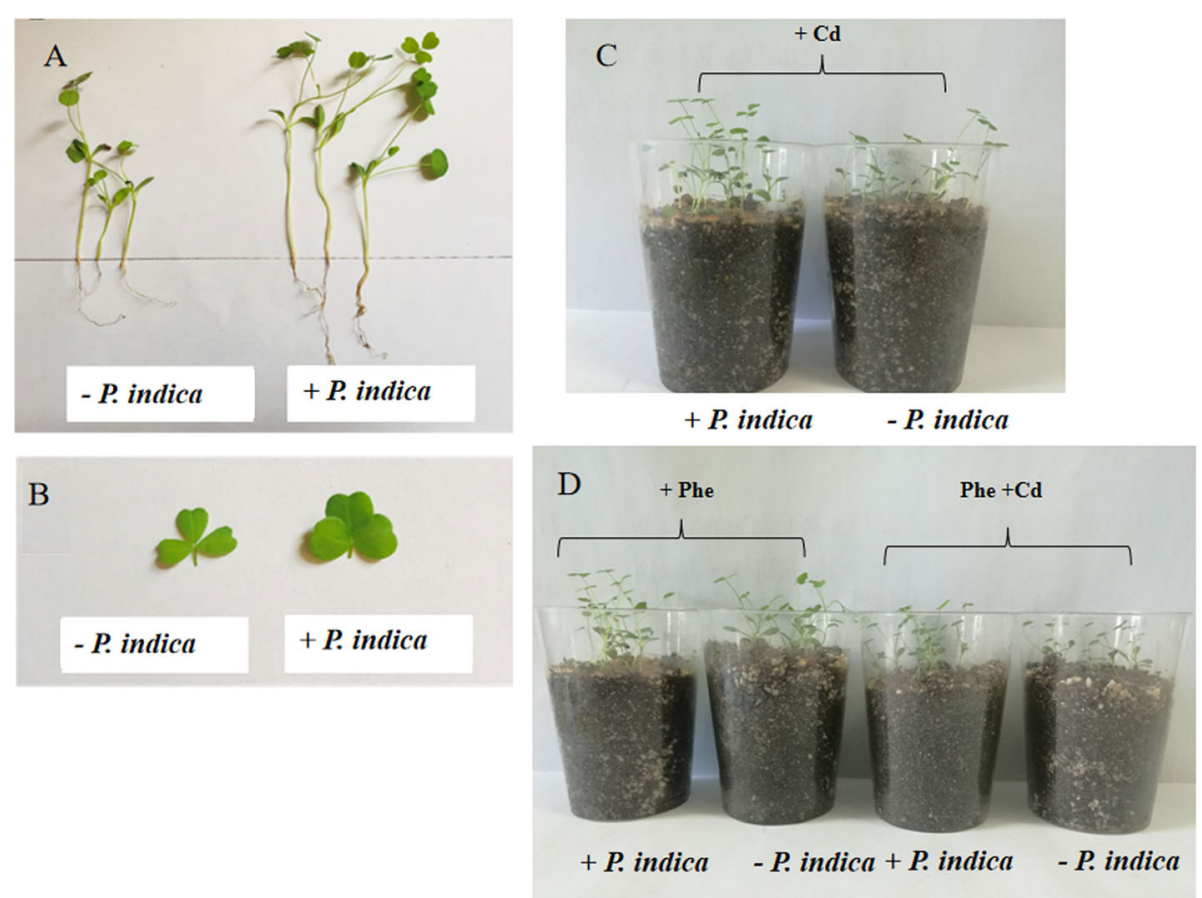

Fig. 1 Biological effects on root and stem in the Phe, $\mathrm{Cd}$ and the combined Phe-Cd contaminated soil with or without $P$. indica inoculation. a Control with or without $P$. indica inoculation. $\mathbf{b}$ : Leaves area were compared between $P$. indica inoculation and non- $P$. indica inoculation without any contamination. c: Above ground parts were compared between $P$. indica inoculation and non- $P$. indica inoculation in $C d$ contaminated soil. d: Above ground parts were compared between $P$. indica inoculation and non-P. indica inoculation in the Phe and the combined Phe-Cd contaminated soil

\section{Chlorophyll (Chl) a and b contents and fluorescence parameters}

The differences in Chl $a$ and Chl $b$ contents between $P$. indica inoculation conditions were significant $(p<0.01)$ when plants were exposed to $\mathrm{Cd}$ and Phe contamination (Table 1). Without Cd or Phe contamination, P. indica-inoculated M. sativa plants had higher leaf $\mathrm{Chl} a$ and $\mathrm{Chl} b$ contents than the noninoculated plants. Both $\mathrm{Cd}$ and Phe contamination significantly reduced the $\mathrm{Chl} a$ and $\mathrm{Chl} b$ contents. The effects of Phe on the Chl $a$ and $\mathrm{Chl} b$ contents were more severe than those of $\mathrm{Cd}$. However, $P$. indica inoculation significantly increased the $\mathrm{Chl} a$ and $\mathrm{Chl} b$ contents under the $\mathrm{Cd}$, Phe, and $\mathrm{Cd}+$ Phe treatments in comparison to those in the noninoculated plants. The presence of $P$. indica significantly reduced F0 so that the F0 values of the inoculated plants were $8,12.9$, and $14 \%$ lower than those of the noninoculated plants under the $\mathrm{Cd}$, Phe, and $\mathrm{Cd}+$ Phe treatments, respectively. Additionally, all three fluorescence parameters, including Fm (maximal fluorescence level in the dark-adapted state), Fv/Fm (maximum quantum efficiency of PSII photochemistry), and ETR (relative PSII electron transport rate), were significantly decreased under the $\mathrm{Cd}$, Phe, $\mathrm{Cd}+$ Phe treatments compared with those of the control. However, a noticeable increase in $\mathrm{Fm}, \mathrm{Fv} / \mathrm{Fm}$, and ETR was observed in P. indica-inoculated $M$. sativa in comparison to noninoculated plants.

\section{$P$. indica auxin production affected by phenanthrene and cadmium}

IAA promotes plant growth at low concentrations and inhibits plant growth at high concentrations. Therefore, we were interested in revealing whether IAA production in $P$. indica would be affected by phenanthrene and cadmium. Qualitative analysis by the Salkowski method showed that after adding tryptophan, the solution containing spores of $P$. indica under each treatment changed to pink in three repetitions, unlike in the control (Fig. 3a-b), which indicated that IAA was produced under the Phe, $\mathrm{Cd}$ and combined Phe and $\mathrm{Cd}$ treatments. Additionally, the IAA content produced by $P$. indica was quantified by HPLC. The results showed that both the Phe and Cd treatments affected IAA production (Fig. 3c). Notably, the combined Phe and Cd treatment resulted in less IAA production $(0.69 \mu \mathrm{M})$. This result explained why the biomass compensation in roots treated with combined Phe and $\mathrm{Cd}$ was less than that in roots treated with only Phe or $\mathrm{Cd}$ though all the roots in these treatments were colonized by $P$. indica (Fig. 1).

\section{$P$. indica inoculation increased FDA activities in nonrhizosphere soil}

The fluorescein diacetate assay (FDA) is an easy and conclusive method for determining soil microorganism activity. Figure 4 shows that FDA activity was higher in $P$. 


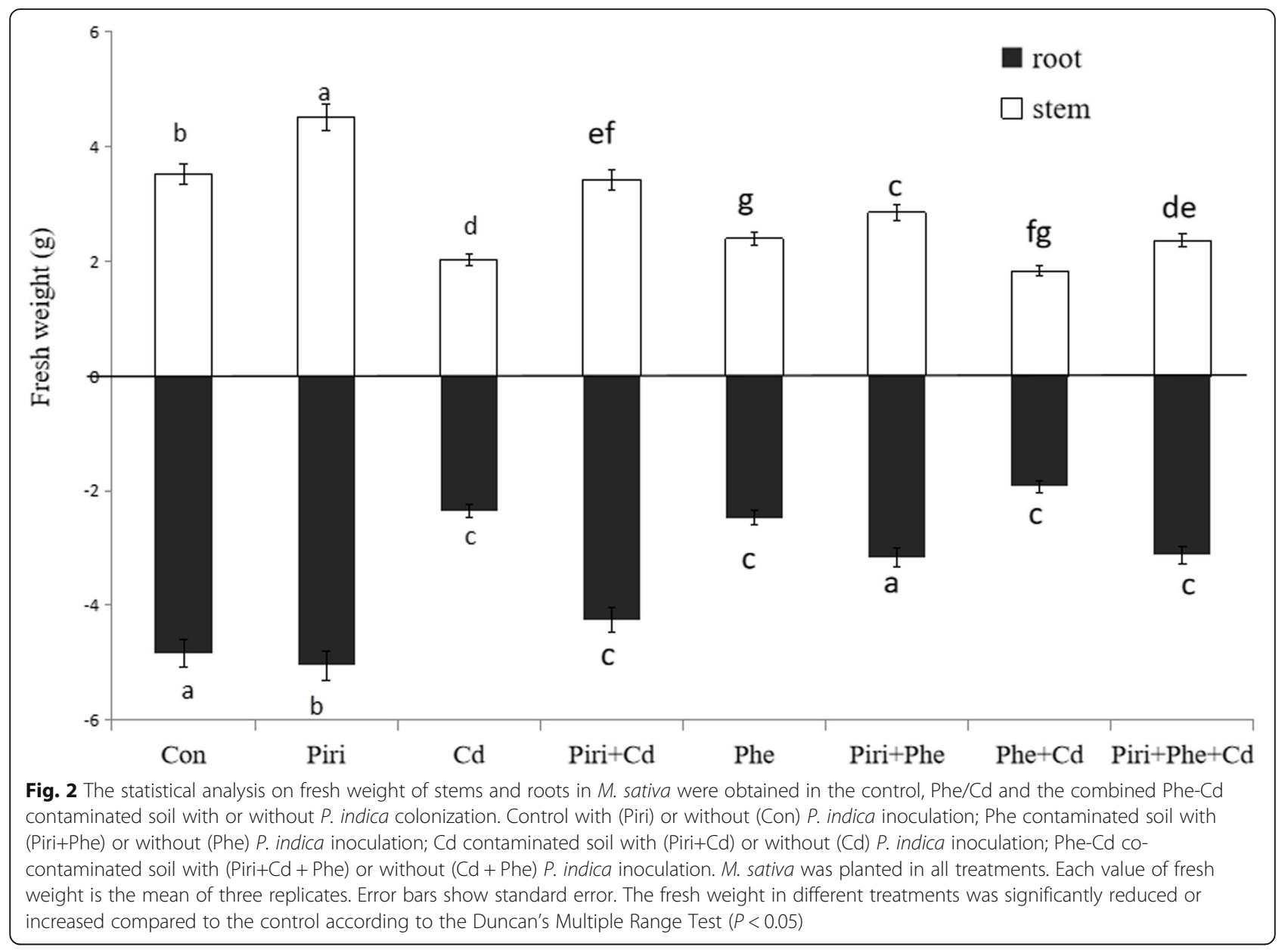

indica-inoculated plants than in noninoculated plants in the combined and individual $\mathrm{Cd}$ and Phe treatments as well as in the control. The FDA activity in the nonrhizosphere under $P$. indica inoculation was the highest, whereas the $\mathrm{Cd}+$ Phe treatment in the nonrhizosphere had the lowest FDA activity. An interesting phenomenon was observed in which $P$. indica colonization in plant roots significantly increased microorganism activity in the nonrhizosphere compared with that in the rhizosphere. $\mathrm{Cd}$ and Phe contamination significantly reduced FDA activity both in the rhizosphere and the nonrhizosphere. In comparing the $\mathrm{Cd}$ and Piri+Cd treatments, no obvious differences in FDA activity were observed in the rhizosphere, and the addition of $P$. indica remarkably increased FDA activity in the nonrhizosphere. Similar results were obtained between the Phe and Piri+Phe treatments.

Table 1 The effects of $P$. indica, Cd and Phe treatments on Chl a, Chl b, FO, Fm, Fv/Fm and ETR in M. sativa

\begin{tabular}{|c|c|c|c|c|c|c|c|}
\hline Fungal treatment & Phe and $\mathrm{Cd}$ treatment & $\begin{array}{l}\text { Chl a } \\
\left(\mathrm{mg} \mathrm{g}^{-1} \mathrm{FW}\right)\end{array}$ & $\begin{array}{l}\mathrm{Chl} \mathrm{b} \\
\left(\mathrm{mg} \mathrm{g}^{-1} \mathrm{FW}\right)\end{array}$ & Fo & $\mathrm{Fm}$ & $\mathrm{Fv} / \mathrm{Fm}$ & ETR \\
\hline \multirow[t]{4}{*}{$-P$} & 0 & $4.57 \pm 0.01^{9}$ & $2.63 \pm 0.02^{a}$ & $0.76 \pm 0.03^{a}$ & $2.78 \pm 0.03$ & $0.74 \pm 0.07^{b}$ & $92.5 \pm 2.4^{c}$ \\
\hline & \multirow{3}{*}{$\begin{array}{l}\text { Cd } \\
\text { Phe } \\
\text { Cd + Phe }\end{array}$} & $3.58 \pm 0.10^{a}$ & $2.10 \pm 0.05^{\mathrm{a}}$ & $0.85 \pm 0.04^{a}$ & $2.66 \pm 0.04^{a}$ & $0.58 \pm 0.07^{c}$ & $88.5 \pm 1.12^{b}$ \\
\hline & & $3.21 \pm 0.02^{b}$ & $1.93 \pm 0.04^{a}$ & $0.93 \pm 0.01^{b}$ & $2.41 \pm 0.02^{b}$ & $0.45 \pm 0.06^{d}$ & $71.6 \pm 2.07^{\mathrm{de}}$ \\
\hline & & $3.10 \pm 0.03^{b}$ & $1.76 \pm 0.02^{b}$ & $1.07 \pm 0.02^{c}$ & $2.17 \pm 0.03^{c}$ & $0.31 \pm 0.05^{\mathrm{e}}$ & $67.5 \pm 3.02^{\mathrm{a}}$ \\
\hline \multirow[t]{4}{*}{$+P$} & 0 & $5.01 \pm 0.02^{c}$ & $2.85 \pm 0.04^{c}$ & $0.63 \pm 0.05^{d}$ & $2.86 \pm 0.04^{d}$ & $0.86 \pm 0.02^{f}$ & $98.3 \pm 3.17^{b}$ \\
\hline & $\mathrm{Cd}$ & $4.26 \pm 0.04^{d}$ & $2.55 \pm 0.06^{d}$ & $0.78 \pm 0.06^{f}$ & $2.72 \pm 0.06^{\mathrm{e}}$ & $0.76 \pm 0.02^{\mathrm{a}}$ & $104 \pm 2.45^{c}$ \\
\hline & Phe & $4.02 \pm 0.02^{\mathrm{e}}$ & $2.41 \pm 0.05^{\mathrm{e}}$ & $0.81 \pm 0.03^{\mathrm{e}}$ & $2.62 \pm 0.05^{f}$ & $0.61 \pm 0.03^{b}$ & $101.1 \pm 3.14^{\mathrm{d}}$ \\
\hline & Cd + Phe & $3.78 \pm 0.04^{f}$ & $2.17 \pm 0.03^{f}$ & $0.92 \pm 0.02^{g}$ & $2.31 \pm 0.03^{g}$ & $0.52 \pm 0.04 c$ & $93.8 \pm 2.53^{\mathrm{e}}$ \\
\hline
\end{tabular}

$-\mathrm{P}$ : non-inoculation (control), $+\mathrm{P}$ : $P$. indica. Values are mean $\pm \mathrm{SE}, n=3$. The same letter within each column indicates no significant difference among treatments using Duncan's Multiple Range Test 

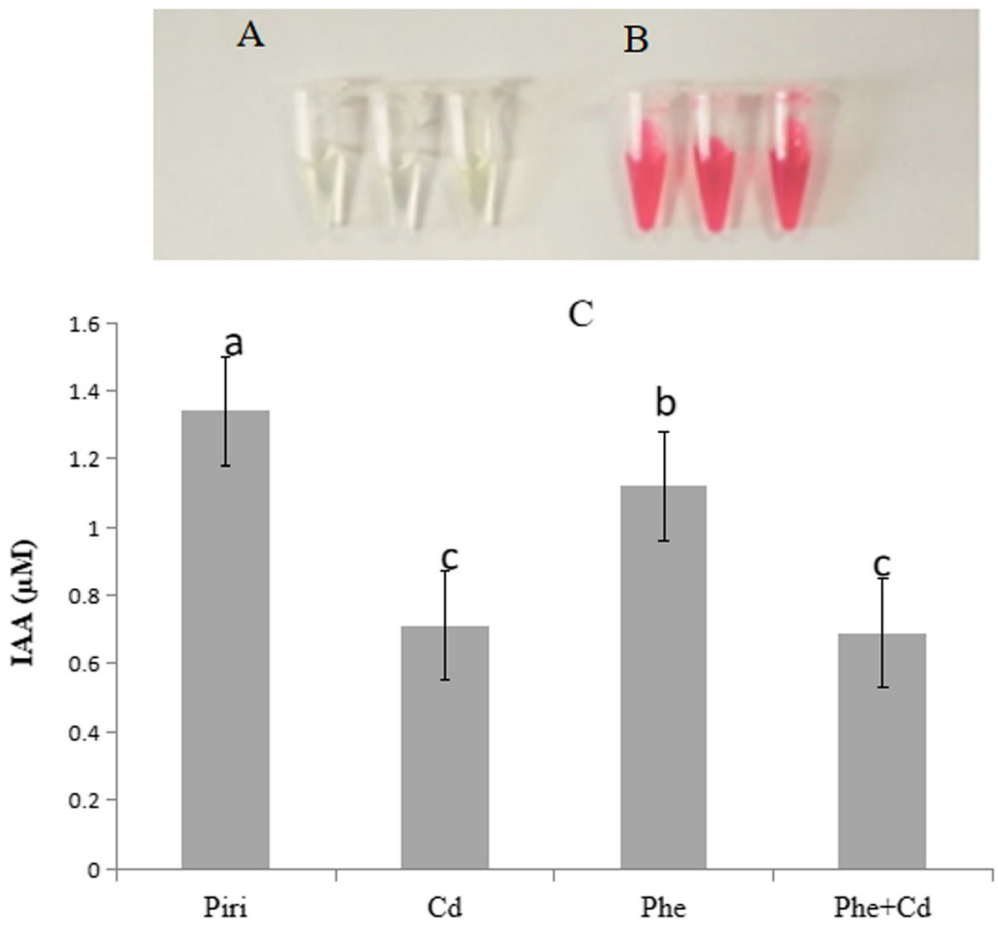

Fig. 3 IAA production of P.indica during growth in CM medium containing the Cd or Phe contamination. Qualitative analysis by the Salkowskimethod was performed to identify IAA production under phenanthrene, cadmium and the combined phenanthrene and cadmium treatments. a: After adding the tryptophan, the solution not containing $P$. indica spores under each treatment does not changed colour in each three repetitions. $\mathbf{b}$ : After adding the tryptophan, the solution containing $P$. indica spores under each treatment changed to pink colour in each three repetitions. c: IAA was determined in culture supernatants by HPLC-MS after 6 weeks containing the $\mathrm{Cd}$, Phe or the combined Cd and Phe contamination medium, respectively. IAA concentrations in CM medium without any contamination were $1.34+0.03 \mu \mathrm{M}(n=3)$; IAA concentrations in the medium containing $\mathrm{Cd}$ were $0.71 \pm 0.05 \mu \mathrm{M}(n=3)$; IAA concentrations in the medium containing Phe were $1.12+0.07 \mu \mathrm{M}$ $(n=3)$; IAA concentrations in the medium containing the combined $\mathrm{Cd}$ and Phe were $0.69 \pm 0.04 \mu \mathrm{M}(n=3)$; respectively. Error bars show standard error. The IAA concentration was significantly reduced in the $\mathrm{Cd}$, Phe and the combined $\mathrm{Cd}+$ Phe treatments compared to the control ( $P$. indica) according to the Duncan's Multiple Range Test $(P<0.05)$

\section{$P$. indica inoculation increased polyphenol oxidase activity in the rhizosphere}

Polyphenol oxidase activity in the rhizosphere and nonrhizosphere is shown in Fig. 5. Polyphenol oxidase activity in the rhizosphere was higher than that in the nonrhizosphere. $P$. indica colonization significantly increased polyphenol oxidase activity in both the rhizosphere and the nonrhizosphere. The order of polyphenol oxidase activity from low to high among the different treatments was $\mathrm{Phe}+\mathrm{Cd}<\mathrm{Phe}<$ $\mathrm{Cd}<$ Piri+Phe $<$ Piri+Phe $+\mathrm{Cd}<$ Piri $+\mathrm{Cd}<$ Con $<$ Piri. These data revealed several findings: 1) polyphenol oxidase activity in soil was more easily affected by Phe than by $\mathrm{Cd}$ contamination; 2) the addition of $P$. indica significantly increased polyphenol oxidase activity in the rhizosphere; 3) in Phe and $\mathrm{Cd}$ cocontaminated soil, the polyphenol oxidase activity was greatly inhibited, whereas after $P$. indica colonization in the $M$. sativa roots, the polyphenol oxidase activity was remarkably enhanced compared with that in the control.

\section{$P$. indica inoculation reduced phenanthrene content in the rhizosphere}

The phenanthrene degradation rates in the rhizosphere and nonrhizosphere were measured (Fig. 6a). Generally, the phenanthrene content in the rhizosphere was lower than that in the nonrhizosphere. In the rhizosphere, among the four different treatments, the phenanthrene concentration in the soil from high to low was $\mathrm{Phe}+\mathrm{Cd}$, Phe, Piri + Phe $+\mathrm{Cd}$, and Piri+Phe. The concentration gradient in the nonrhizosphere was similar to that in the rhizosphere. These data imply that $P$. indica colonization effectively reduced phenanthrene content in soil.

To support this evidence, the phenanthrene concentrations in plant roots and stems were also measured. The phenanthrene concentrations in roots were $135 \pm 6$ $\mathrm{mg} \mathrm{kg}{ }^{-1}, 165 \pm 4 \mathrm{mg} \mathrm{kg}^{-1}, 108 \pm 10 \mathrm{mg} \mathrm{kg}^{-1}$, and $156 \pm 7$ $\mathrm{mg} \mathrm{kg}^{-1}$ among the Phe, Piri+Phe, Phe $+\mathrm{Cd}$ and Piri + Phe + Cd treatments, respectively (Fig. 6b). Notably, the phenanthrene concentrations in roots were higher than those in stems. The Phe $+\mathrm{Cd}$ treatment had the lowest phenanthrene content in the stem compared to 


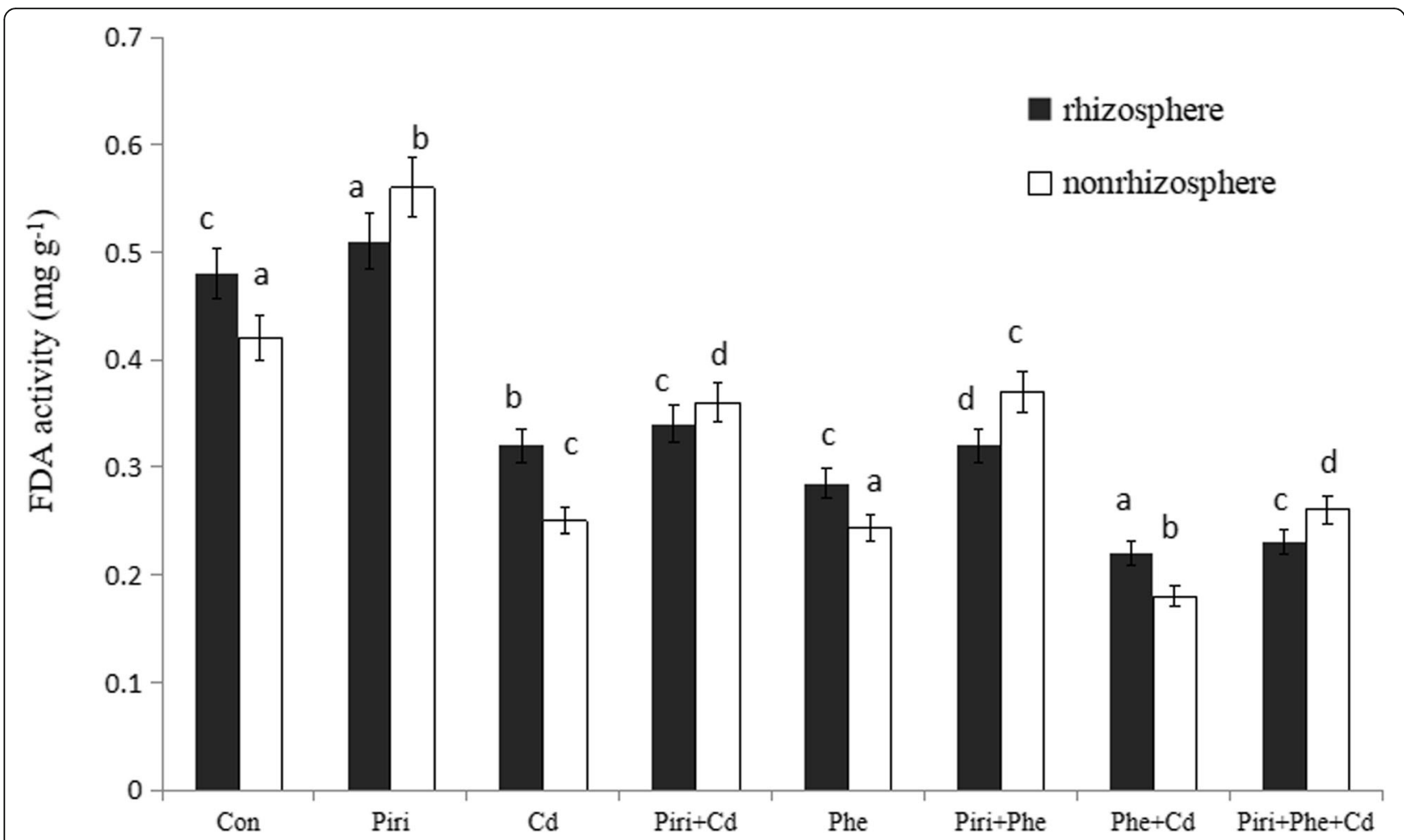

Fig. 4 The FDA activities were identified in the control, Phe/Cd and the combined Phe-Cd contaminated soil with or without $P$. indica colonization. Control with (Piri) or without (Con) P. indica inoculation; Phe contaminated soil with (Piri+Phe) or without (Phe) P. indica inoculation; Cd contaminated soil with (Piri+Cd) or without (Cd) P. indica inoculation; Phe-Cd co-contaminated soil with (Piri+Cd + Phe) or without (Cd + Phe) P. indica inoculation. M. sativa was planted in all the treatments. Each value of FDA activities is the mean of three replicates. Error bars show standard error. For the control, Cd, Phe and the combined Cd + Phe treatments, FDA activity in the nonrhizosphere was significantly reduced compared with that in the rhizosphere; For the Piri, Piri+Cd, Piri+Phe and Piri+Cd + Phe treatments, FDA activity in nonrhizosphere was significantly increased compared with that in the rhizosphere; for Control and Piri, $\mathrm{Cd}$ and Piri+Cd, Phe and Piri+Phe, Phe $+\mathrm{Cd}$ and Piri+Phe $+\mathrm{Cd}$, the adding of $P$. indica spores significantly increases the FDA activity both in the rhizosphere and nonrhizosphere compared with that in the treatment without $P$. indica inoculation. Different letters a-d in the columns indicate significant difference in FDA activities between treatments according to the Duncan's Multiple Range Test $(P<0.05)$

the other treatments. There was no striking difference in the stem phenanthrene content among the Phe, Piri+Phe and Piri+Phe + Cd treatments.

\section{$P$. indica inoculation reduced cadmium content in the rhizosphere}

The cadmium content in the rhizosphere and nonrhizosphere was measured and is shown in Fig. 7a. Similarly, the cadmium content in the rhizosphere was less than that in the nonrhizosphere. In the rhizosphere, among the four different treatments, the cadmium concentration from high to low was Phe $+\mathrm{Cd}$, Piri $+\mathrm{Phe}+\mathrm{Cd}, \mathrm{Cd}$, and Piri $+\mathrm{Cd}$. Adding $P$. indica spores significantly reduced the cadmium content in comparison to that in the treatment without $P$. indica inoculation. For instance, in both the rhizosphere and the nonrhizosphere, the Piri+Cd treatment had a lower cadmium content than the Cd treatment, and the Piri+Phe $+\mathrm{Cd}$ treatment had a lower cadmium content than the Phe $+\mathrm{Cd}$ treatment. Remarkably, the Cd content in the rhizosphere of the $P$. indica treatment was significantly lower (less than $\left.2 \mathrm{mg} \mathrm{kg}^{-1}\right)$ than the original $\mathrm{Cd}$ content in the soil (10 $\left.\mathrm{mg} \mathrm{kg}^{-1}\right)$. The cadmium concentration gradient in the nonrhizosphere was similar to that in the rhizosphere. These data imply that colonization with $P$. indica effectively reduced the cadmium content in soil.

Additionally, the cadmium concentrations in plant roots and stems were explored (Fig. 7b). The cadmium concentrations in roots were $30 \pm 4 \mathrm{mg} \mathrm{kg}^{-1}, 34 \pm 6 \mathrm{mg}$ $\mathrm{kg}^{-1}, 23 \pm 8 \mathrm{mg} \mathrm{kg}^{-1}$, and $29 \pm 5 \mathrm{mg} \mathrm{kg}^{-1}$ in the Cd, Pir$\mathrm{i}+\mathrm{Cd}$, Phe $+\mathrm{Cd}$ and Piri + Phe $+\mathrm{Cd}$ treatments, respectively. Likewise, the cadmium concentrations in roots were notably higher than those in stems. In stems, the $\mathrm{Cd}$ content showed a different trend from the phenanthrene content: the Piri $+\mathrm{Cd}$ treatment had a lower $\mathrm{Cd}$ content than the $\mathrm{Cd}$ treatment, and the $\mathrm{Cd}$ content in the Piri+Phe $+\mathrm{Cd}$ treatment was lower than that in the Phe $+\mathrm{Cd}$ treatment. This result suggested that inoculation with $P$. indica inhibited the transport of $\mathrm{Cd}$ into the stem. 


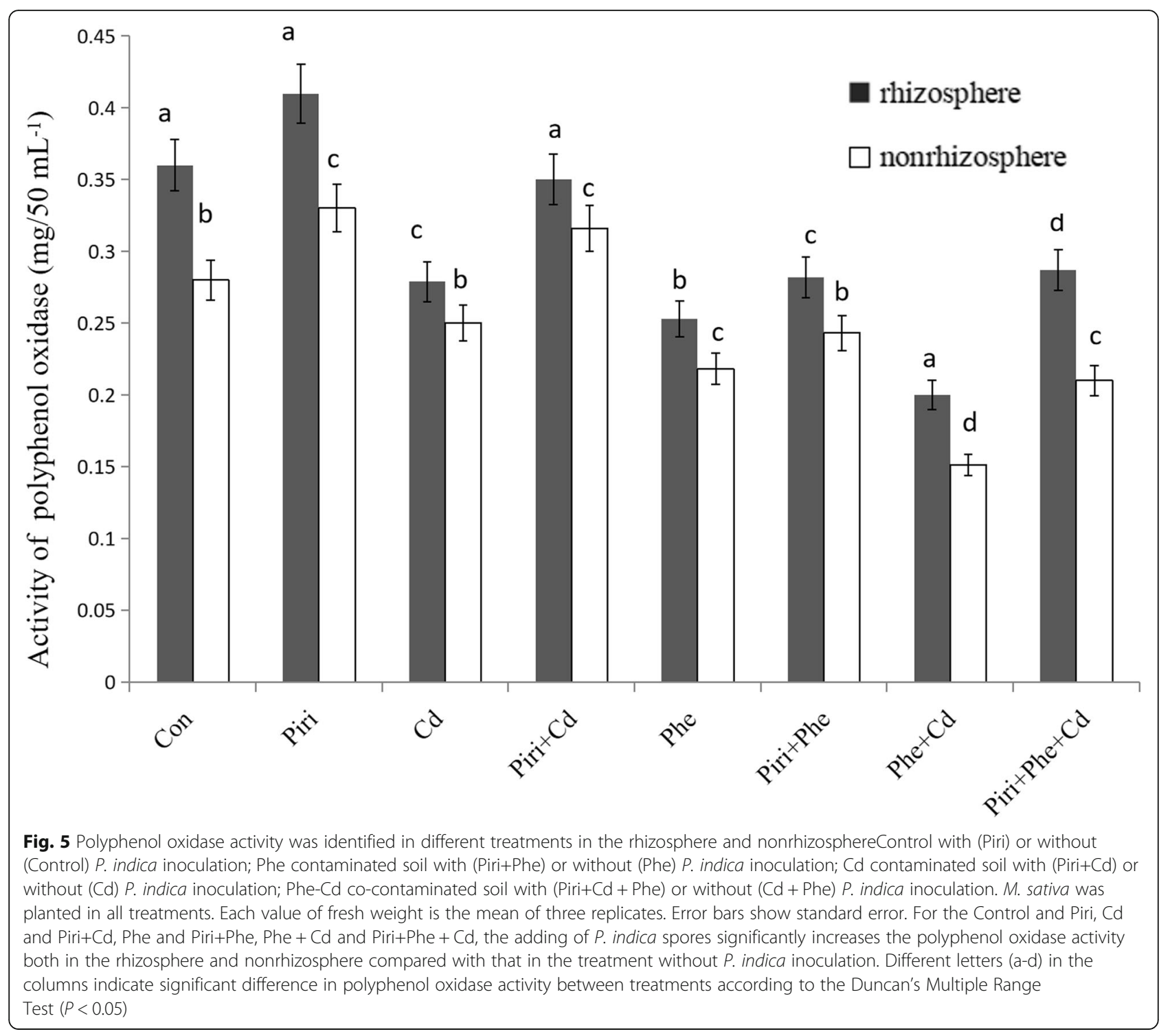

\section{Discussion}

Heavy metal and organic pollutants in soil severely harm plant growth and development. Cd treatment substantially inhibits plant biomass accumulation. Shahabivand et al. [34] reported that $P$. indica successfully colonized plants grown in $120 \mathrm{mg} \mathrm{kg}^{-1} \mathrm{Cd}$-contaminated soil, which suggests that this fungus was able to colonize roots under high $\mathrm{Cd}$ stress in soil. However, we found that the spore germination and hyphal growth of $P$. indica were seriously inhibited under $40 \mathrm{mg} \mathrm{kg}^{-1} \mathrm{Cd}$ (data not shown). Therefore, $10 \mathrm{mg} \mathrm{kg}^{-1} \mathrm{Cd}$ was selected as the test concentration.

Our data indicated that colonization with $P$. indica in the $\mathrm{Cd}\left(10 \mathrm{mg} \mathrm{kg}^{-1}\right)$, Phe $\left(40 \mathrm{mg} \mathrm{kg}^{-1}\right)$ and $\mathrm{Phe}+\mathrm{Cd}$ treatments relieved the stress from heavy metals and PAHs. Though the $\mathrm{Cd}$ concentration in the roots of the Piri $+\mathrm{Cd}$ treatment was higher than that in the $\mathrm{Cd}$ treatment, the biomass was not significantly affected. The results implied that a high concentration of $\mathrm{Cd}$ could be fixed or isolated to some degree by this fungus and plant co-living system which would therefore reduce the harmful effects to the plants. Cd accumulation in stems was reduced after phenanthrene contamination in soil, which indicated that the organic pollutants accumulated in roots might hinder $\mathrm{Cd}$ transport from roots to aboveground parts. The Piri+Phe treatment accumulated a high concentration of phenanthrene in the roots, which decreased the biomass of the roots and stems compared to that in the Piri treatment. However, even the high concentration of phenanthrene in roots did not hinder the growth promotion effect of $P$. indica on host plants compared to the growth of plants in the Phe treatment. This result was different from a previous report that the accumulation of pyrene by plant-growth- 

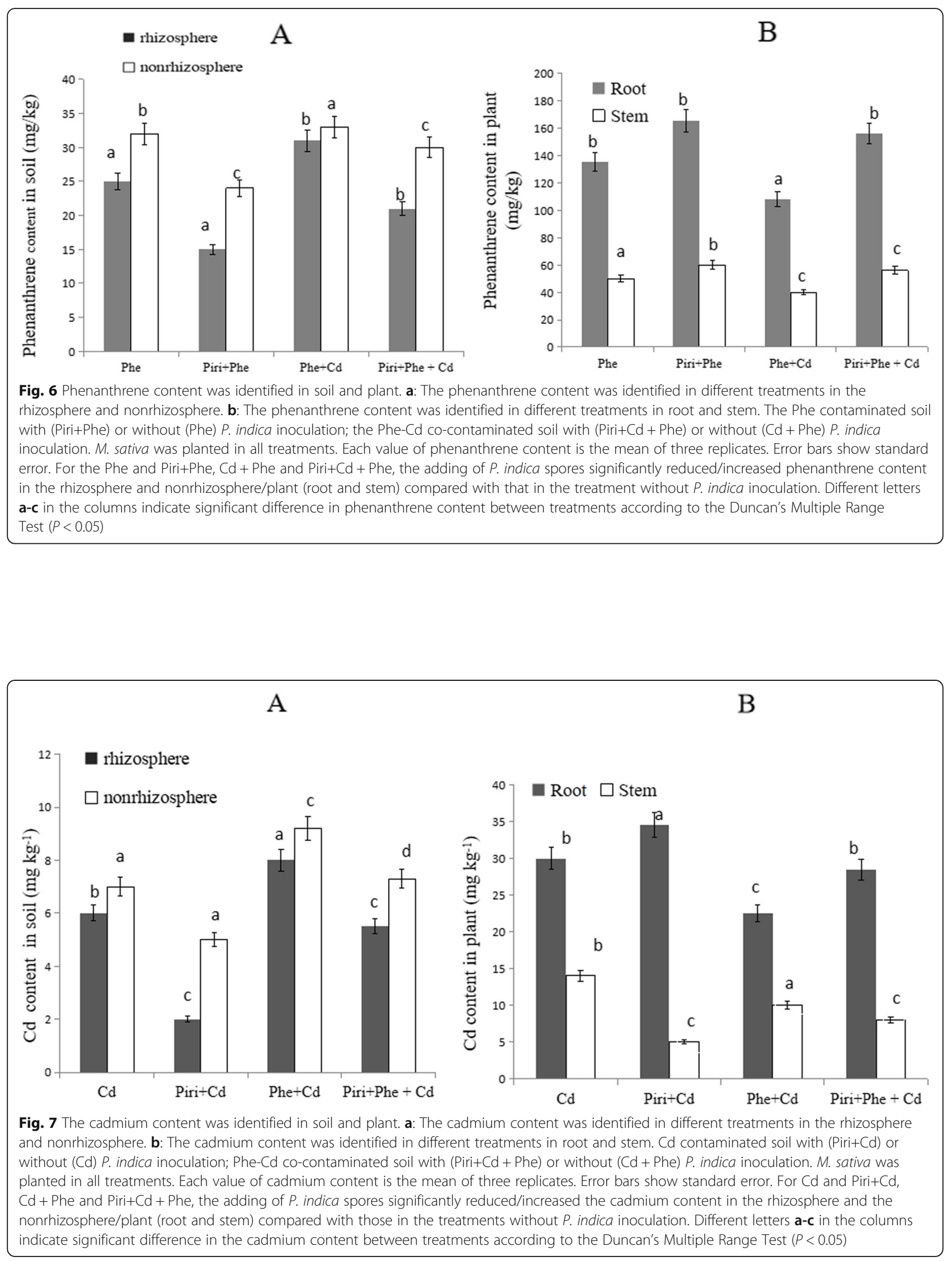
promoting bacteria (PGPB) decreased stem biomass [32]. One possible reason for this different result is that the endophytic fungus, unlike the bacteria, could accumulate and tolerate the phenanthrene, thereby reducing its toxicity to plants.

$M$. sativa plants subjected to $\mathrm{Cd}$ and Phe stress showed reduced growth in terms of shoot and root length and shoot and root fresh weight. The toxic effects of $\mathrm{Cd}$ have widely been reported in different plant species, and $\mathrm{Cd}$ is known to reduce or inhibit plant growth because of the harmful impact of $\mathrm{Cd}$ on the processes of photosynthesis, respiration and essential element uptake [34, 35]. Chaoui and Ferjani (2005) [36] reported that the activity of indole-3-acetic acid (IAA) oxidase (as a growth-limiting enzyme) was increased under $\mathrm{Cd}$ toxicity, which resulted in reduced plant growth due to the diminution of the endogenous content of the plant growth-promoting hormone auxin. In our work, the elevation in host photosynthetic efficiency via increased Chl $a$ and $b$ contents and elevated $\mathrm{Fv} / \mathrm{Fm}$ and ETR values (Table 1) contributed to the $P$. indica-induced growth promotion and stress tolerance.

Soil microorganism activity can effectively reflect soil fertility. The soil microorganism activity was determined in order to speculate on phytoremediation efficiency. We noticed that the FDA activity in the nonrhizosphere was higher than that in the rhizosphere in the $P$. indicacolonized plants. One possible reason for this result is that, due to the presence of $P$. indica in the plant roots, much more heavy metal accumulated in the rhizosphere than in the nonrhizosphere, which resulted in harmful effects on microorganisms and therefore reduced FDA activity in the rhizosphere. The FDA activity in the $P$. indica treatment was higher than that in the non- $P$. indica treatment in both the rhizosphere and the nonrhizosphere. The Phe treatment had lower FDA activity than the Cd treatment, which was in accordance with a previous report that petroleum hydrocarbons inhibit microorganism activity in soil [37]. Though similar FDA activities were observed in the rhizosphere in the $\mathrm{Cd}$ and Piri+Cd or Phe and Piri+Phe treatments, the mechanisms of FDA activity might be different. The reduction in FDA activity in the $\mathrm{Cd}$ and Phe treatments was probably due to heavy metal or PAH stress, whereas the reduction in FDA activity in the Piri+Cd or Piri+Phe treatments was probably due to the inhibition of phytopathogen growth. Enzymes are part of the soil composition, and the degree of their activity sensitively reflects the direction and strength of biochemical reactions in soil [38]. The changes in enzyme activity effectively reflect the ability of microorganisms and plant roots to degrade organic pollutants in soil. In our experiment, we detected the activity of several enzymes, including urease and invertase, and the results indicated that these enzymes were more active in the rhizosphere of $P$. indica-colonized roots than in the rhizosphere of noninoculated plants (data not shown). Polyphenol oxidase is an important oxidoreductase enzyme in soil that participates in the process of decomposition and transformation of aromatic compounds. The enhanced polyphenol oxidase activity in this study implied that $P$. indica has a strong ability to remediate contaminated soil.

Co-contamination with heavy metals and PAHs resulted in a deleterious influence on microorganism activity in soil compared to that under individual heavy metal or PAH contamination [39], which explained why the Phe $+\mathrm{Cd}$ treatment had the lowest FDA activity in all treatments. The Piri+Cd and Piri+Phe $+\mathrm{Cd}$ treatments had higher FDA activity than the $\mathrm{Cd}$ and Phe $+\mathrm{Cd}$ treatments, respectively, which implied that the endophyte and plant co-living system contributed to a wellestablished microecosystem for microorganisms in soil.

In the Phe, Piri+Phe, $\mathrm{Cd}+\mathrm{Phe}$ and Piri $+\mathrm{Phe}+\mathrm{Cd}$ treatments, Phe accumulation in plants was $135 \pm 6 \mathrm{mg}$ $\mathrm{kg}^{-1}, 165 \pm 4 \mathrm{mg} \mathrm{kg}^{-1}, 108 \pm 10 \mathrm{mg} \mathrm{kg}^{-1}$, and $156 \pm 7$ $\mathrm{mg} \mathrm{kg}^{-1}$, respectively. The high concentration of Phe in plants means that less Phe remained in the soil. In addition to plants, soil microorganisms play key roles in the removal of PAHs. In the Phe $+\mathrm{Cd}$ treatment, the Phe concentrations remaining in the rhizosphere and nonrhizosphere were higher than those in the Phe treatment, which was reasonable due to the higher microorganism activity in the Phe treatment. Though no significant difference in FDA activity was detected between the Phe and Phe + Piri treatments, $P$. indica colonization obviously reduced the Phe concentration in the rhizosphere and the nonrhizosphere. Similar data were collected from the Phe $+\mathrm{Cd}$ and $\mathrm{Phe}+\mathrm{Cd}+$ Piri treatments. In total, the Phe concentration in the rhizosphere was lower than that in the nonrhizosphere, suggesting that the rhizosphere effect was responsible for the lower accumulation of PAHs in the rhizosphere soil than in the nonrhizosphere soil [40].

The order of $\mathrm{Cd}$ concentrations in roots from high to low was as follows: Piri $+\mathrm{Cd}, \mathrm{Cd}$, Piri $+\mathrm{Phe}+\mathrm{Cd}$, and Phe $+\mathrm{Cd}$. The data indicated that $P$. indica colonization increased $\mathrm{Cd}$ accumulation in roots. However, in comparing the Piri $+\mathrm{Cd}$ and Piri+Phe $+\mathrm{Cd}$ treatments, it was notable that the addition of Phe reduced $\mathrm{Cd}$ accumulation into a certain degree. The bioavailability of heavy metals determines phytoremediation efficiency [41]. Microorganisms in soil, such as fungi and bacteria, are capable of producing biosurfactants such as rhamnolipids that can increase the mobility of heavy metals to enhance their bioavailability [42]. Therefore, it was reasonable that $P$. indica colonization significantly reduced the $\mathrm{Cd}$ concentration in the rhizosphere compared with that in the nonrhizosphere. On the other hand, plant root 
exudates also contribute to the acidification of heavy metals, which increases the efficiency of phytoremediation. P. indica colonization significantly promoted root growth and development, and the roots in turn secreted exudates to increase the bioavailability of heavy metals and enhance phytoremediation efficiency in the rhizosphere, forming a virtuous cycle.

\section{Conclusions}

In conclusion, $P$. indica colonization had positive effects on photosynthetic processes and increased the tolerance of $M$. sativa in soil contaminated with phenanthrene, cadmium, and combined cadmium and phenanthrene, especially in soil only contaminated with cadmium. The phenanthrene and cadmium co-contaminated soil affected soil microorganisms more severely than individual phenanthrene or cadmium contamination. $P$. indica inoculation in $M$. sativa roots increased the FDA activity in soils contaminated with phenanthrene, cadmium and both pollutants, especially in the nonrhizosphere. The addition of $P$. indica stimulated the roots of $M$. sativa to accumulate higher concentrations of phenanthrene and cadmium, thereby enhancing phytoremediation efficiency. A clear diagram of our conclusions about the phytoremediation effect of $M$. sativa colonized by $P$. indica on soil co-contaminated with phenanthrene and cadmium is provided in Fig. 8. This study suggests that the application of $P$. indica combined with $M$. sativa could contribute to the remediation of PAH-metal cocontaminated soil for sustainable agriculture.

\section{Methods}

\section{Plant materials}

Medicago sativa seeds were provided by Professor Diter Von Wettstein, Department of Crop and Soil Sciences, Washington State University.

\section{Chemicals}

Phenanthrene with a purity of $98 \%$ was purchased from Sigma (USA). The rest of the chemicals were purchased from Dingguo (Tian Jin, China).

\section{Soil used in the study}

The experimental soil had never been contaminated by PAHs or heavy metals and was collected from the topsoil $(0-20 \mathrm{~cm})$ at Hebei University of Technology, China. The soil is a phaeozem (alfisol) from Hebei Province [43]. The test soil was sieved with a $2 \mathrm{~mm}$ sieve after being air-dried. The soil samples were measured using standard methods [44] before phytoremediation. The composition of the sample soil was physico-chemically characterized: $55.6 \pm 2.1 \%$ silt, $30.8 \pm 1.8 \%$ sand and $13.6 \pm 1.5 \%$ clay; $0.06 \%$ total $\mathrm{N}, 8 \mathrm{mg} / \mathrm{kg}$ available $\mathrm{P}, 40$ $\mathrm{mg} / \mathrm{kg}$ available $\mathrm{K}$, and $1.1 \%$ organic matter. The soil $\mathrm{pH}$ was $7.36 \pm 0.06$.

\section{Preparation of phenanthrene-contaminated soil}

Phenanthrene was dissolved in acetone and added to a small part of the soil. One day later, after the acetone had volatilized, a small part of the soil was added to the whole sample soil and incorporated thoroughly. The

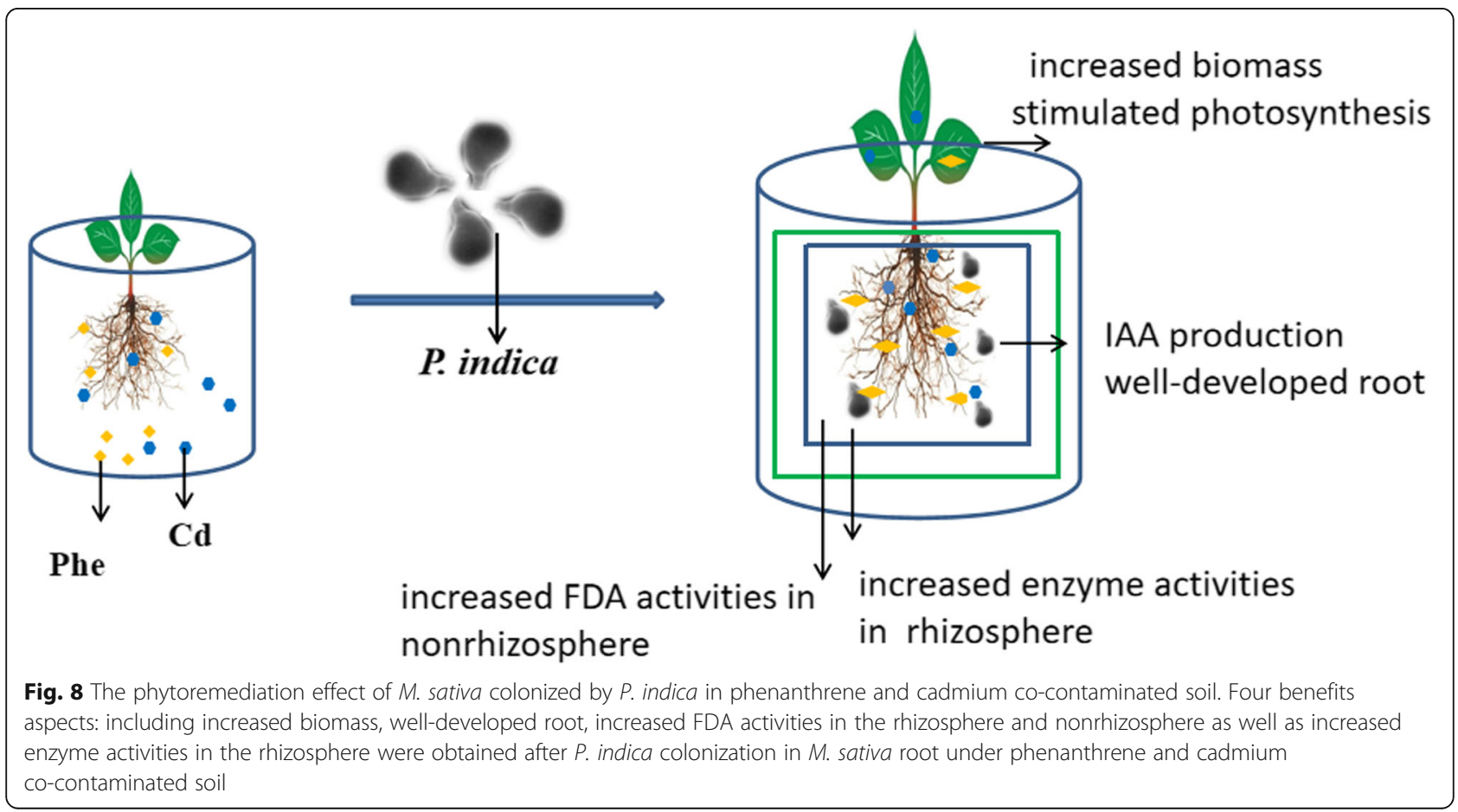


final concentration of phenanthrene in the soil was measured as $40 \pm 3 \mathrm{mg} \mathrm{kg}^{-1}$.

\section{Preparation of cadmium-contaminated soil}

An aqueous solution of cadmium nitrate was added to the prepared soil, and the final concentration of cadmium in the soil was measured as $10 \pm 2 \mathrm{mg} \mathrm{kg}^{-1}$.

\section{Preparation of phenanthrene and cadmium co- contaminated soil}

The acetone stock solution containing phenanthrene was first added to the test soil. After the acetone evaporated, the cadmium nitrate aqueous solution was added to the soil previously polluted by phenanthrene. The final concentrations of cadmium and phenanthrene in the soil were measured as $10 \pm 2 \mathrm{mg} \mathrm{kg}^{-1}$ and $40 \pm 3 \mathrm{mg}$ $\mathrm{kg}^{-1}$, respectively. The prepared soil and a control soil without any pollution were moved into boxes and aged in the dark for 15 days.

\section{Fungal culture}

In this work, the P. indica isolate DSM11827 (German collection of microorganisms and cell cultures in Braunschweig, Germany) was applied. The P. indica was supplied by Karl-Heinz-Kogel (Institute of Plant Pathology and Applied Zoology, Giessen, Germany). The P. indica was maintained at $23^{\circ} \mathrm{C}$ on $\mathrm{CM}$ medium [45]. For solid medium, $14 \mathrm{~g} \mathrm{~L}^{-1}$ agar was added; for liquid cultures, $100 \mathrm{~mL}$ medium was inoculated in a 300-mL Erlenmeyer flask. To test whether $\mathrm{Cd}$ and Phe would affect IAA production, $5 \mathrm{mg} \mathrm{kg}^{-1}$ and $20 \mathrm{mg} \mathrm{kg}^{-1}$ cadmium and phenanthrene, respectively, were added to the liquid cultures. The CM medium was inoculated with 20 mycelium plugs from the margin of a growing colony of $P$. indica on $\mathrm{CM}$ solid medium. The liquid cultures were incubated at $23^{\circ} \mathrm{C}$ at $150 \mathrm{rpm}$ on a rotary shaker.

\section{Quantification of IAA in fungal growth media by HPLC}

The IAA production ability of $P$. indica under the Phe, $\mathrm{Cd}$ and Phe $+\mathrm{Cd}$ treatments was measured using the Salkowski method according to the literature [46]. The quantification of IAA in the fungal growth media was performed by HPLC. Fungal culture filtrates were harvested, acidified and extracted twice with ethyl acetate as described in [29]. The parameters used for HPLC were as follows: $50 \%$ methanol: $45 \%$ water: $5 \%$ acetonitrile (v/ v) was used as the mobile phase. A flow rate of $0.2 \mathrm{~mL}$ $\min ^{-1}$ was applied. The injection volume was $10 \mu \mathrm{l}$. The column temperature was kept at $40{ }^{\circ} \mathrm{C}$. The IAA content was quantified by Agilent HPLC equipped with an $\mathrm{HC}^{\mathrm{R}}$ C18 $(5 \mu \mathrm{m}, 4.6 \times 250 \mathrm{~mm}$, Agilent, USA) reverse-phase chromatographic column. The IAA concentrations were always determined in parallel in medium in which no fungus had been cultured but which had been incubated under the same conditions.

\section{M. sativa treatment and $P$. indica inoculation}

$P$. indica grown on CM medium plates for 3-4 weeks was used for the preparation of the spore suspensions. To collect spores from the CM agar plates, sterilized water containing $0.05 \%$ Tween-20 was added. The spores were released by gently scratching the surface of plates with a spatula, and the suspension solution was filtered through Miracloth (Calbiochem, Bad Soden, Germany) to remove the mycelium. After that, spores were collected by centrifuging the suspension solution at $3500 \mathrm{rpm}$ for $7 \mathrm{~min}$. Then, the spores were washed at least 3 times with sterilized Tween-H2O. By using a hemacytometer in combination with a microscope, the spore densities were determined. The spore concentration was adjusted to 500,000 spores $/ \mathrm{mL}$ with sterilized Tween-H2O. For inoculation, $3 \mathrm{~mL}$ spore suspension was pipetted on top of plant roots in a square Petri dish. The seeds of $M$. sativa were surface-sterilized in $70 \%$ alcohol for $1 \mathrm{~min}$ and then in $3 \% \mathrm{NaClO}$ for $15 \mathrm{~min}$. After sterilization, seeds were repeatedly washed with sterile deionized water and planted in the MS medium [47] for germination. After 7 days, when roots had grown, $P$. indica spores were added to the root surface. Then, the seedlings containing $P$. indica spores were transferred into the different types of soil in pots $(5 \mathrm{~kg})$. Three replicates were applied for each treatment.

The plants were rejuvenated in the shade for 1 week. Then, the pots were transferred to a greenhouse with natural light and watered daily to maintain soil moisture (approximately $300 \mathrm{~mL}$ water/pot). Three months later, the plants were harvested, and soil from the rhizosphere and nonrhizosphere of $M$. sativa was collected.

\section{Measurement of chlorophyll contents and chlorophyll fluorescence}

Chlorophyll content in the youngest fully expanded leaves $(0.1 \mathrm{~g})$ was extracted by $80 \%$ acetone and centrifuged at $4000 \mathrm{rpm}$ for $20 \mathrm{~min}$; the optical density of the supernatant was read at 663 and $645 \mathrm{~nm}$ wavelengths for $\mathrm{Chl} a$ and $\mathrm{Chl} b$, respectively [48]. The following parameters of chlorophyll fluorescence were measured by analyzing the first fully grown leaves of $M$. sativa using a portable fluorometer (Hansatech, Instruments LTD, UK): F0 (minimal fluorescence level in the dark-adapted state), Fm (maximal fluorescence level in the darkadapted state), Fv/Fm (maximum quantum efficiency of PSII photochemistry) and ETR (the relative PSII electron transport rate). $M$. sativa plants were dark-adapted for $30 \mathrm{~min}$ to measure the influence of the experimental factors on photosystem II (PSII) efficiency. 


\section{Measure of soil microorganism activity}

Soil microorganism activity was measured according to methods in the literature [31]. First, the soil was freezedried by a freeze-drying machine (Alpha 1-2 L D plus, Germany). Five grams of freeze-dried soil was dissolved in $15 \mathrm{~mL}$ of phosphate buffer solution $(\mathrm{NaCl}-8.5 \mathrm{~g}$, $\left.\mathrm{Na}_{2} \mathrm{HPO}_{4}-2.2 \mathrm{~g}, \quad \mathrm{NaH}_{2} \mathrm{PO}_{4}-0.1 \mathrm{~g}, \quad \mathrm{pH} 7.6\right)$ at room temperature. The turbid liquid was shaken at $180 \mathrm{rpm}$ for $30 \mathrm{~min}$, and then $0.5 \mathrm{~mL}$ of fluorescein diacetate (FDA) (2 $\mathrm{g} \mathrm{L}^{-1}$, in acetone) solution was added into the mixture. The absorbance value was recorded at $\mathrm{OD}_{490 \mathrm{~nm}}$.

\section{Analysis of phenanthrene in the rhizosphere and nonrhizosphere}

A three-step sequential extraction method was used to detect the concentrations of phenanthrene in different chemical speciations in the soil [40]. The ultrasonic extraction and high-performance liquid chromatography (HPLC) ultraviolet detection method was used. Ten grams of freeze-dried soil sample was dissolved in $50 \mathrm{~mL}$ of acetone-hexane $(1: 1, \mathrm{v} / \mathrm{v})$ mixed extraction solvent. The extraction process was performed for $1 \mathrm{~h}$ in the ultrasonic cleaner. The extracted liquid was poured into a filter funnel containing $10 \mathrm{~g}$ anhydrous $\mathrm{Na}_{2} \mathrm{SO}_{4}$. The extracted liquid was concentrated to $5 \mathrm{~mL}$ by a rotary evaporation instrument in a $60^{\circ} \mathrm{C}$ water bath. Then, 5 $\mathrm{mL}$ concentrated extracted liquid was transferred to a silica gel-alumina column for chromatography and eluted with a methylene chloride-hexane $(1: 1, \mathrm{v} / \mathrm{v}) \mathrm{mix}-$ ture. The condensed elution was nearly dried, diluted to a final volume of $1 \mathrm{~mL}$ and used for HPLC determination. The parameters used for HPLC were as follows: methanol and water $(87: 13, \mathrm{v} / \mathrm{v})$ were used as the mobile phase. A flow rate of $1 \mathrm{~mL} \mathrm{~min}^{-1}$ and detection wavelength of 254 $n m$ were applied. The content of phenanthrene was quantified by Agilent HPLC equipped with an $\mathrm{HC}^{\mathrm{R}} \mathrm{C} 18(5 \mu \mathrm{m}$, $4.6 \times 250 \mathrm{~mm}$, Agilent, USA) reverse-phase chromatographic column. The phenanthrene recovery from soil was $97 \pm 3 \%$.

\section{Analysis of phenanthrene in plants}

The phenanthrene in plants was extracted by acetone and dichloromethane (v/v, 1:1). After centrifugation and rotary evaporation, the concentrated phenanthrene was exchanged with $1 \mathrm{~mL}$ hexane for analysis. The content of phenanthrene was quantified by HPLC equipped with an $\mathrm{HC}^{\mathrm{R}} \mathrm{C} 18(5 \mu \mathrm{m}, 4.6 \times 250 \mathrm{~mm}$, Agilent, USA $)$ reverse-phase chromatographic column. The oven temperature was first maintained at $100^{\circ} \mathrm{C}$ for $2 \mathrm{~min}$, then increased to $300{ }^{\circ} \mathrm{C}$ at a rate $10{ }^{\circ} \mathrm{C} \mathrm{min}^{-1}$, and finally kept at $300^{\circ} \mathrm{C}$ for $10 \mathrm{~min}$. A phenanthrene standard was added to the uncontaminated plants and soil to measure phenanthrene recovery. A procedural blank as well as a spiked blank and duplicate samples were included every batch of 10 samples in the analysis. The phenanthrene recovery from plants was $99 \pm 5 \%$.

\section{Analysis of cadmium in soil and plants}

Cadmium was determined according to methods in the references $[40,49]$. Soil from the rhizosphere and nonrhizosphere of $M$. sativa was extracted by mixing $0.5 \mathrm{~g}$ soil with $10 \mathrm{~mL} \mathrm{HCl}$ solution and then heating for $3 \mathrm{~h}$ $\left(45^{\circ} \mathrm{C}\right)$. After cooling, cadmium was extracted by mixing the soil with $\mathrm{HNO}_{3}$ and $\mathrm{HClO}_{4}(\mathrm{v} / \mathrm{v}, 4: 1)$ for digestion $\left(220^{\circ} \mathrm{C}, 1 \mathrm{~h}\right)$ and then adding $\mathrm{HF}$ and $\mathrm{HClO}_{4}(\mathrm{v} / \mathrm{v}, 5: 1)$ for further digestion $\left(220^{\circ} \mathrm{C}, 2 \mathrm{~h}\right)$. The same method was used to extract cadmium from the plants. At the end of the extraction step, the supernatant was harvested by centrifuging at $6000 \mathrm{rpm}$ for $20 \mathrm{~min}$. Then, the supernatant was filtered through a $0.45 \mu \mathrm{m}$ microfiltration membrane and quantified by inductively coupled plasma optical emission spectrometry (ICPOES).

\section{Analysis of enzyme activity in the rhizosphere and nonrhizosphere}

The enzyme activity of polyphenol oxidase was determined according to the soil enzyme analytical methods manual [50]. Ten grams of freeze-dried soil was dissolved in $10 \mathrm{~mL}$ pyrogallol (1\%) and shaken at $150 \mathrm{rpm}$ $\min ^{-1}$ for $1 \mathrm{~min}$. Then, the sample was kept in the dark at $30^{\circ} \mathrm{C}$ for $2 \mathrm{~h}$. Four milliliters of citric acid-phosphate buffer (disodium hydrogen phosphate- $35.61 \mathrm{~g} \mathrm{~L}^{-1}$, citric acid-21.01 $\left.\mathrm{g} \mathrm{L}^{-1}, \mathrm{pH} 4.5\right)$ was added to the sample. Finally, $35 \mathrm{~mL}$ ether was added and shaken for $2 \mathrm{~min}$. The absorbance value at $430 \mathrm{~nm}$ was recorded after $30 \mathrm{~min}$ of extraction.

\section{Statistical analysis}

In this study, all data are expressed as the means $\pm \mathrm{SE}$ and represent at least three independent biological experiments. The significance of differences was analyzed by using one-way analysis of variance (ANOVA) with Duncan's multiple range test.

\section{Abbreviations}

AMF: Arbuscular mycorrhizal fungi; Cd: cadmium; Chl: a/ Chl bChlorophyll (Chl) $a, b$; ETR: The relative PSII electron transport rate; FO: Minimal

fluorescence level in the dark-adapted state; FDA: Fluorescein diacetate assay; Fm: Maximal fluorescence level in the dark-adapted state; Fv/ Fm: Maximum quantum efficiency of PSII photochemistry; IAA: Indole-3acetic acid; M. sativa: Medicago sativa; PAHs: Polycyclic aromatic hydrocarbons; P. indica: Piriformospora indica; PGPM: Plant growth promoting microorganism; Phe: Phenanthrene

\section{Acknowledgements}

We would like to express deep thanks to Professor Karl-Heinz Kogel for providing the fungus of $P$. indica and guidance for this research work. We also showed our thanks to the anonymous reviewers for their helpful. comments on the manuscript.

\section{Authors' contributions}

L. L. designed and guided the whole experiment, also performed the work of analyzing the data and writing the manuscript. P. Z. was responsible for 
the $M$. sativa and $P$. indica cultivation. $X W$. was responsible for the phenanthrene (Phe) and cadmium (Cd) co-contaminated soil preparation and Fluorescein diacetate (FDA) activities analysis. Z. Z. performed the Cd and Phe concentration analysis in soil and other relative work. All authors read and approved the final manuscript.

\section{Funding}

We thank Scientific Research Fund of Department of Education of Hebei Province (Grant No. QN2018014) and National Natural Science Foundation of China(Grant No. 31801948) as well as Key R\&D Projects in Hebei Province (Grant No. 19226505D) for financial supports.

\section{Availability of data and materials}

The datasets used and/or analyzed during the current study are available. from the corresponding author on reasonable request.

\section{Ethics approval and consent to participate}

This study does not involve any human or animal testing. Medicago sativa seeds were provided by Professor Diter Von Wettstein, Department of Crop and Soil Sciences, Washington State University.

\section{Consent for publication}

$$
\text { Not applicable. }
$$

\section{Competing interests}

The authors declare that they have no competing interests.

\section{Author details}

'School of Chemical Engineering and Technology, Hebei University of Technology, Tianjin 300130, China. ${ }^{2}$ National-Local Joint Engineering Laboratory for Energy Conservation of Chemical Process Integration and Resources Utilization, Tianjin, China. ${ }^{3}$ School of Environmental Science and Engineering, Tianjin University, Tianjin 300072, China.

Received: 9 July 2019 Accepted: 21 April 2020

Published online: 28 April 2020

\section{References}

1. Mansour SA, Gad MF. Risk assessment of pesticides and heavy metals contaminants in vegetables: a novel bioassay method using daphnia magna Straus. Food Chem Toxicol. 2010;48(1):377-89.

2. Rezek J, Wiesche CID, Mackova M, Zadrazil F, Macek T. The effect of ryegrass (Lolium perenne) on decrease of PAH content in long term contaminated soil. Chemosphere. 2008;70(9):1063-608.

3. Obuekwe IS, Semple KT. Impact of zinc-copper mixtures on the development of phenanthrene catabolism in soil. Int Biodeterior Biodegrad. 2013;85(11):228-36.

4. Ehsan S, Ali S, Noureen S, Mahmood K, Farid M, Ishaque W. Citric acid assisted phytoremediation of cadmium by brassica Napus L. Ecotoxicol Environ Saf. 2014;106:164-72.

5. Adediran GA, Ngwenya BT, Mosselmans JF, Heal KV, Harvie BA. Mechanisms behind bacteria induced plant growth promotion and $\mathrm{Zn}$ accumulation in brassica juncea. J Hazard Mater. 2015;283:490-9.

6. Palaniyandi SA, Yang SH, Zhang L, Suh JW. Effects of actinobacteria on plant disease suppression and growth promotion. Appl Microbiol Biotechnol. 2013;97(22):9621-36

7. Li Y, Liu K, Wang Y, Zhou Z, Chen C, Ye P, Yu F. Improvement of cadmium phytoremediation by Centella asiatica L. after soil inoculation with cadmium-resistant Enterobacter sp. FM-1. Chemosphere. 2018:202:280-8.

8. Yang T, Lin XG, Hu JL, Zhang J, Lu JL, Wang JH. Effects of arbuscular mycorrhizal fungi on phytoremediation of PAHs-contaminated soil by Medicago sativa and Lolium multiflorum. Ecol Rural Environt. 2009;25(4):72-6.

9. Tamayo E, Gómez-Gallego T, Azcón-Aguilar C, Ferrol N. Genome-wide analysis of copper, iron and zinc transporters in the arbuscular mycorrhizal fungus Rhizophagus irregularis. Front Plant Sci. 2014;5:547.

10. Verma S, Varma A, Rexer KH, Hassel A, Kost G, Sarbhoy A. Piriformospora indica, gen. Et sp. nov., a new root-colonizing fungus. Mycologia. 1998;90(5): 896-903.

11. Weiss M, Selosse M-A, Rexer K-H, Urban A, Oberwinkler F. Sebacinales: a hitherto overlooked cosm of heterobasidiomycetes with a broad mycorrhizal potential. Mycol Res. 2004;108:1003-10.
12. Varma A, Verma S, Sudha SN, Butehorn B, Franken P. Piriformospora indica, a cultivable plant-growthpromoting root endophyte. Appl Environ Microbiol. 1999;65:2741-4.

13. Shahollari B, Varma A, Oelmuller R. Expression of a receptor kinase in Arabidopsis roots is stimulated by the basidiomycete Piriformospora indica and the protein accumulates in triton X-100 insoluble plasma membrane microdomains. J Plant Physiol. 2005;162(8):945-58.

14. Deshmukh S, Hueckelhoven $R$, Schäfer P, Imani J, Sharma M, Weiss M, Waller $\mathrm{F}$, Koge KH. The root endophytic fungus Piriformospora indica requires host cell death for proliferation during mutualistic symbiosis with barley. Proc Natl Acad Sci. 2006:103:18450-7.

15. Zhang XY, Liu XY, Liu SS, Liu FH, Chen LS, Xu G. Response characteristics of Scirpus trioueter and its rhizosphere to pyrene contaminated soils at different growth stages. Int J Phytorem. 2012;14(7):691-702.

16. Das A, Kamal S, Shakil NA, Sherameti I, Oelmüller R, Dua M. The root endophyte fungus Piriformospora indica leads to early flowering, higher biomass and altered secondary metabolites of the medicinal plant, coleus forskohlii. Plant Signal Behav. 2012;7(1):103-12.

17. Li L, Chen X, Ma C, Wu H, Qi S. Piriformospora indica requires kaurene synthase activity for successful plant colonization. Plant Physiol Biochem. 2016:102:151-60.

18. Vahabi K, Camehl I, Sherameti I. Growth of Arabidopsis seedlings on high fungal doses of Piriformospora indica has little effect on plant performance, stress, and defense gene expression in spite of elevated jasmonic acid and jasmonic acid-isoleucine levels in the roots. Plant Signal Behav. 2013;8: 26301-11.

19. Varma A, Sherameti I, Tripathi S, Prasad R, Das A, Sharma M, Bakshi M, Johnson JM, Bhardwaj S, Arora M, Rastogi K, Agrawal A, Kharkwal AC, Talukdar S, Bagde US, Bisaria VS, Upadhyaya CP, Won PS, Chen Y, Ma J, Lou B, Adya AK, Zhong L, Meghvanshi MK, Gosal SK, Srivastava RB, Johri AK, Cruz C, Oelmüller R. The symbiotic fungus Piriformospora indica. In: Hock B, editor. Fungal associations, The Mycota ix. 2nd ed. Germany: Verlag, Berlin Heidelberg; 2012. p. 231-54.

20. Ghabooli M, Khatabi B, Ahmadi FS, Sepehri M, Mirzaei M, Amirkhani A Proteomics study reveals the molecular mechanisms underlying water stress tolerance induced by Piriformospora indica in barley. J Proteome. 2013; 94(20):289-301.

21. Sherameti I, Tripathi S, Varma A, Oelmüller R. The root-colonizing endophyte Pirifomospora indica confers drought tolerance in Arabidopsis by stimulating the expression of drought stress-related genes in leaves. Mol Plant-Microbe Interact. 2008;21(6):799-807.

22. Jogawat A, Saha S, Bakshi M, Dayaman V, Kumar M, Dua M. Piriformospora indica rescues growth diminution of rice seedlings during high salt stress. Plant Signal Behav. 2013;8:26891.

23. Waller F, Achatz B, Baltruschat H, Fodor J, Becker K, Fischer M. The endophytic fungus Piriformospora indica reprograms barley to salt-stress tolerance, disease resistance, and higher yield. Proc Natl Acad Sci. 2005; 102(38):13386-91.

24. Schäfer P, Kogel KH. The Sebacinoid fungus Piriformospora indica: an orchid mycorrhiza which may increase host plant reproduction and fitness. Plant Relationship. 2009:5:99-112.

25. Chen T, Liu X, Zhang X, Chen X, Tao K, Hu X. Effect of alkyl polyglucoside and nitrilotriacetic acid combined application on lead/pyrene bioavailability and dehydrogenase activity in co-contaminated soils. Chemosphere. 2016; 154:515-20

26. Hou Y, Liu X, Zhang X, Chen X, Tao K, Chen X. Identification of Scirpus triqueter root exudates and the effects of organic acids on desorption and bioavailability of pyrene and lead in co-contaminated wetland soils. Environ Sci Pollut Res Int. 2015;22(22):17780-8.

27. Juwarkar AA, Nair A, Dubey KV, Singh SK, Devotta S. Biosurfactant technology for remediation of cadmium and lead contaminated soils. Chemosphere. 2007:68(10):1996-2002.

28. Braud A, Jézéquel $K$, Vieille E, Tritter A, Lebeau T. Changes in extractability of $\mathrm{Cr}$ and $\mathrm{Pb}$ in a polycontaminated soil after bioaugmentation with microbial producers of biosurfactants, organic acids and siderophores. Water Air Soil Pollut. 2006:6(3-4):261-79.

29. Sirrenberg A, Gobe C, Grond S. Piriformospora indica affects plant growth by auxin production Physiol. Planta. 2007:131:581-9.

30. Gaonkar T, Bhosle S. Effect of metals on a siderophore producing bacteria isolate and its implications on microbial assisted bioremediation of metal contaminated soils. Chemosphere. 2013;93(9):1835-43. 
31. Tribedi P, Sil AK. Bioaugmentation of polyethylene succinate-contaminated soil with pseudomonas, sp. AKS2 results in increased microbial activity and better polymer degradation. Environ Sci Pollut Res. 2013;20:1318-26.

32. Chen X, Liu X, Zhang X, Cao L, Hu X. Phytoremediation effect of Scirpus triqueter inoculated plant-growth-promoting bacteria (PGPB) on different fractions of pyrene and Ni in co-contaminated soils. J Hazard Mater. 2017; 325:319-26

33. Johnson DL, Mcgrath SP. Soil microbial response during the phytoremediation of PAH contaminated soil. Soil Biol Biochem. 2005;37(12): 2334-6.

34. Shahabivand S, Parvaneh A, Aliloo AA. Root endophytic fungus Piriformospora indica affected growth, cadmium partitioning and chlorophyll fluorescence of sunflower under cadmium toxicity. Ecotox. Environ Safe. 2017; 145:496-502.

35. Guo HP, Hong CT, Chen XM, Xu YX, Liu Y, Jiang D, Zheng BS. Different growth and physiological responses to cadmium of the three Miscanthus species. PLoS One. 2016;11:e0153475.

36. Chaoui A, Ferjani EE. Effects of cadmium and copper on antioxidant capacities, lignification and auxin degradation in leaves of pea (Pisum sativum L.) seedlings. Plant biol. Pathol. 2005;328:23-31.

37. Zhang $X$, Chen L, Liu X, Wang C, Chen X, Xu G. Synergic degradation of diesel by Scirpus triqueter and its endophytic bacteria. Environ Sci Pollut Res. 2014;21(13):8198-205.

38. Liu SL, Luo YM, Wu LH. Degradation of phenanthrene in soil planted with ryegrass and the effect of phenanthrene on soil enzymes. Acta Pedol Sin. 2009:46(3):419-25.

39. Maliszewska-Kordybach B, Smreczak B. Habitat function of agricultural soils as affected by heavy metals and polycyclic aromatic hydrocarbons contamination. Environ Int. 2003;28(8):719-28.

40. Wang $Q$, Liu $X$, Zhang $X$, Hou $Y$, Hu X, Liang X. Influence of tea saponin on enhancing accessibility of pyrene and cadmium phytoremediated with Lolium multiflorum in co-contaminated soils. Environ Sci Pollut Res. 2016; 23(6):5705-11.

41. Megharaj M, Ramakrishnan B, Venkateswarlu K, Sethunathan N, Naidu R. Bioremediation approaches for organic pollutants: a critical perspective. Environ Int. 2011;37(8):1362-75.

42. Mulligan CN. Environmental applications for biosurfactants. Environ Pollut. 2005;133(2):183-98.

43. Soil Survey Staff, Keys to Soil Taxonomy. 11th ed. USDA-Natural Resources Conservation Service, Washington, DC. 2010.

44. Lu R K. Analytical methods of soil agriculture chemistry. China Agricultural Science and Technology Press, Beijing. 1999.

45. Pham GH, Kumar R, Singh A, Malla R, Prasad R, Sachdev M, Kaldorf M, Buscot F, Ölmüller R, Hampp R, Saxena AK, Rexer KH, Kost G, Varma A. Axenic culture of symbiotic fungus Piriformospora indica. In: Varma A, Abbot L, Werner D, Hampp R, editors. Plant surface microbiology. Heidelberg: Springer-Verlag. Berlin; 2004. p. 593-612.

46. Glickmann E, Dessaux YA. Critical examination of the specificity of the salkowski reagent for indole compounds produced by phytopathogenic bacteria. Appl Environ Microbiol. 1995;61:793-6.

47. Murashige T, Skoog F. A revised medium for rapid growth and bioassays with tobacco tissue culture. Physiol Plant. 1962;15:473-97.

48. Arnon A. Method of extraction of chlorophyll in the plants. Agron J. 1967; 23:112-21.

49. Tessier A, Campbell PGC, Bisson M. Sequential extraction procedure for the speciation of particulate trace metals. Anal Chem. 1979;51(7):844-51.

50. Guan S Y. Soil enzymes and analytical methods. Beijing: Agric press 1986.

\section{Publisher's Note}

Springer Nature remains neutral with regard to jurisdictional claims in published maps and institutional affiliations.

\section{Ready to submit your research? Choose BMC and benefit from:}

- fast, convenient online submission

- thorough peer review by experienced researchers in your field

- rapid publication on acceptance

- support for research data, including large and complex data types

- gold Open Access which fosters wider collaboration and increased citations

- maximum visibility for your research: over $100 \mathrm{M}$ website views per year

At BMC, research is always in progress.

Learn more biomedcentral.com/submissions 